\title{
Sequential Development of Long-Term Potentiation and Depression in Different Layers of the Mouse Visual Cortex
}

\author{
Bin Jiang, Mario Treviño, and Alfredo Kirkwood \\ Mind/Brain Institute and Department of Neurosciences, Johns Hopkins University, Baltimore, Maryland 21218
}

\begin{abstract}
Visual deprivation affects the responses of layer IV cells more prominently during early postnatal development, whereas responses in layer II/III remain modifiable until later ages. We examined whether these laminar differences correlate with changes in long-term potentiation (LTP) and long-term depression (LTD) of the ascending pathways to layers IV and II/III in the mouse visual cortex. Our analysis revealed that LTP and LTD in layer IV principal cells is lost shortly after the eyes open, but persists in layers II/III beyond puberty. These results suggest that plasticity proceeds sequentially through cortical layers in a manner that parallels the flow of information during sensory processing.
\end{abstract}

Key words: critical period; layer IV; layer II/III; LTP; LTD; plasticity

\section{Introduction}

Mechanisms of activity-dependent synaptic plasticity like longterm potentiation (LTP) and long-term depression (LTD) are attractive candidates to mediate functional modifications induced by experience in visual and other sensory cortices (Bear et al., 1987). Two prominent features of visual cortical plasticity are that experience affects function more profoundly during a short postnatal critical period, and that the timing of the critical period varies across cortical layers. It is not understood whether the laminar differences in critical period are corresponded by laminar differences in LTP and LTD.

In the visual cortex of felines and primates, and also in the barrel cortex of rodents, the initiation and termination of the critical period for observing the effects of sensory deprivation is earlier in layer IV than in layers II/III (Daw et al., 1992). Indeed, layers II/III of rodent visual and barrel cortex retain substantial capacity for plasticity in adulthood. In the barrel cortex, layer IV cells lose their capacity to express LTP and LTD shortly after birth, whereas pyramidal cells in layer II/III are capable of supporting LTP and LTD throughout adulthood (Crair and Malenka, 1995; Feldman et al., 1998; Glazewski et al., 1998).

In the visual cortex, the effects of age on LTP and LTD in the different layers are less clear. An early critical period for LTD in layer IV cells of visual cortex has been described for cats and guinea pigs (Dudek and Friedlander, 1996a). However, in vivo stimulation of thalamocortical afferents can induce LTP of layer

\footnotetext{
Received Sept. 30, 2006; revised July 23, 2007; accepted July 30, 2007.

This work was supported by National Institutes of Health Grant R01-EY12124. We thank Drs. H. K. Lee, S. Hsiao, and E. Quinlan for critically reviewing this manuscript, and Dr. F. Lee and W. Liu for their assistance with collecting data in some of the experiments.

Correspondence should be addressed to Alfredo Kirkwood, Mind/Brain Institute and Department of Neurosciences, Department of Psychological and Brain Sciences, Johns Hopkins University, 3400 North Charles Street, Baltimore, MD 21218. E-mail: Kirkwood@jhu.edu.

B. Jiang's present address: Brain Science Institute, RIKEN 2-1, Hirosawa, Wako, Saitama 351-0198, Japan. D0I:10.1523/JNEUROSCI.2655-07.2007

Copyright $\odot 2007$ Society for Neuroscience $\quad$ 0270-6474/07/279648-05\$15.00/0
}

IV synaptic sinks in adult rats (Heynen and Bear, 2001). Discrepancies have also been reported for synaptic plasticity in layer II/III. The capacity for LTP was initially thought to persist in adulthood (Kirkwood et al., 1995), but previous reports suggest it is lost in rats after the fifth week (Yoshimura et al., 2003). Similarly, we have reported a developmental loss of LTD in layer II/III in mouse visual cortex (Kirkwood et al., 1997; Choi et al., 2002), whereas others have reported that there are no age-related changes in layer II/III of rat visual cortex (Sermasi et al., 1999). The possible absence of synaptic plasticity mechanisms in adults is intriguing in light of previous studies indicating a substantial ocular dominance plasticity in adult mice (Sawtell et al., 2003; Pham et al., 2004; Tagawa et al., 2005). The apparent dissociation between LTP/LTD and ocular dominance plasticity argues against causality linking these two kinds of plasticity.

Traditional extracellular methods to induce LTP and LTD are sensitive to stimulation parameters, which vary with age, synapse location, and species. We therefore re-examined the developmental changes in LTP and LTD in layers IV and II/III of the mouse visual cortex using whole-cell recording approaches, to allow control of the crucial variable of postsynaptic depolarization. We report that LTP and LTD are lost shortly after eye opening in layer IV and persist beyond puberty in layers II/III. These findings support the notion that the critical period for synaptic plasticity proceeds in a sequential manner through the cortical layers.

\section{Materials and Methods}

Coronal visual cortical slices $(300-400 \mu \mathrm{m})$ from 1- to 8-week-old male C57BL/6J mice were prepared as described previously (Kirkwood et al., 1997) in ice-cold dissection buffer [containing (in mM) 212.7 sucrose, 5 $\mathrm{KCl}, 1.25 \mathrm{NaH}_{2} \mathrm{PO}_{4}, 3 \mathrm{MgCl} 2,1 \mathrm{CaCl} 2,26 \mathrm{NaHCO} 3$, and 10 dextrose, $95 \% \mathrm{O}_{2} / 5 \% \mathrm{CO}_{2}$ ] and transferred to artificial CSF (ACSF) for more than $1 \mathrm{~h}$ before recording. ACSF is similar to the dissection buffer except that sucrose is replaced by $124 \mathrm{~mm} \mathrm{NaCl}, \mathrm{MgCl} 2$ is lowered to $1 \mathrm{~mm}$, and $\mathrm{CaCl} 2$ is raised to $2 \mathrm{~mm}$.

Visualized whole-cell recordings from pyramidal cells in layer IV and 
A

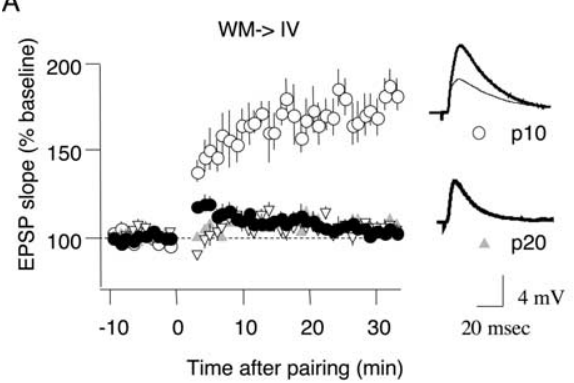

C

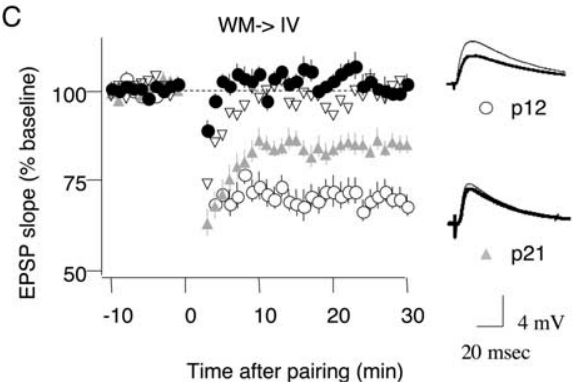

B

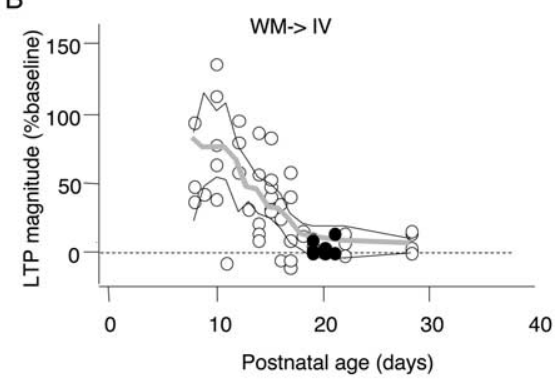

D

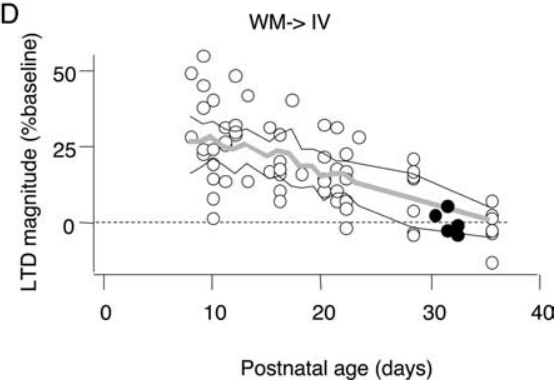

Figure 1. Critical period for pairing induced LTP and LTD of WM $\rightarrow I V . A, L T P$ by pairing $(0 \mathrm{mV})$ in cells from dark-reared mice aged P8 -P12 (open circles; $n=8$ mice, 15 slices), P18 -P23 (gray triangles; $n=5$ mice, 12 slices), and P18 -P23 (filled circles; $n=4,8$ ), and cells recorded with DNDS-containing electrodes (inverted triangles; $n=4$ mice, 7 slices). $\boldsymbol{B}$, Developmental changes in the magnitude of LTP. Individual experiments are represented as open circles. Filled circles represent data from dark-reared animals. The gray line represents a running average made over $5 \mathrm{~d}$ centered on each plotted age data point. Black lines show the $95 \%$ confidence interval. C, LTD induced by pairing $(-40 \mathrm{mV})$ in cells from dark-reared mice aged P8 -P12 (open circles; $n=12$ mice, 20 slices), P18-P23 (gray triangles; $n=10$ mice, 17 slices), P25-P31 (inverted triangles; $n=6$ mice, 10 slices), and P28 -P31 (filled circles; $n=$ 3,6). D, Developmental changes in the LTD magnitude. Open circles, Individual experiments; gray line, running averages ( $5 \mathrm{~d}$ ). Traces in $A$ and $C$ are the averages of 10 consecutive responses recorded just before (thin line) and 28 min after conditioning (thick line) in cells from normal-reared animals of the indicated ages.

Layer II/III were done with pipettes $(2-4 \mathrm{M} \Omega$ ) filled with internal solution consisting of (in $\mathrm{mm}$ ) $130 \mathrm{~K}$-gluconate, $8 \mathrm{NaCl}, 0.2 \mathrm{EGTA}, 10$ HEPES, 3 ATP, 10 Na-phosphocreatine, and 0.5 GTP, pH 7.4, 275-285 mOsm, to record EPSPs. IPSCs were recorded under voltage clamp $(-60$ $\mathrm{mV}$ ) in the presence of $10 \mu \mathrm{M} \mathrm{CNQX}$, and with K-gluconate substituted by $\mathrm{CsCl}$ and $3 \mathrm{~mm}$ QX-314 (lidocaine $N$-ethyl bromide) in the intracellular solution. The junction potential was not compensated. Cells were discarded if the membrane potential was more than $-65 \mathrm{mV}$, the input resistance $<100 \mathrm{M} \Omega$, the access resistance $>20 \mathrm{M} \Omega$, or if the resistance values [monitored with a negative current pulse $(100-400 \mathrm{~ms}, 10-50$ $\mathrm{pA}$ ) applied $200 \mathrm{~ms}$ before synaptic stimulation] changed by $>20 \%$ during the experiment.

For layer IV recordings, we targeted cells located at an $~ 35-50 \%$ depth from the pia; for layer II/III, we targeted cells $>35 \%$ from the pia. Pyramidal cells were identified visually by their shape (pyramidal somata and prominent apical dendrites) and by their regular spiking pattern in response to depolarizing current $(0.1-0.5 \mathrm{nA}, 1 \mathrm{~s})$. To check these criteria, 50 pyramidal-like cells were filled with a fluorescent dye $(0.1 \%$ Lucifer yellow or $1 \%$ Alexa red in the recording pipette). We found that 37 of 38 filled cells in layer IV and 12 of 12 filled cells in layer II/III were pyramidal, thus validating the visual and electrophysiological criteria. These dye-filled cells were not assessed for synaptic plasticity.

Synaptic responses were recorded at $30 \pm 1^{\circ} \mathrm{C}$ and evoked with $0.2 \mathrm{~ms}$ current pulses delivered with a bipolar stimulating electrode $(200 \mu \mathrm{m}$ diameter; FHC, Bowdoin, ME) positioned at the white matter for layer IV recordings, and in the middle of the cortical thickness (roughly at the border between layer IV and layer V) for layer II/III recordings. Synaptic responses (2-5 $\mathrm{mV}$ amplitude) were quantified as the initial slope of the postsynaptic potential (PSP). In some experiments $4,4^{\prime}$-dinitro-stilbene2,2'-disulphonic acid (DNDS; $0.5 \mathrm{~mm}$ ) was included to block chloride channels (Dudek and Friedlander, 1996b). In these cases, the EPSP amplitude grew rapidly after breaking the seal, likely reflecting the diffusion of the drug, and the stimulus intensity was readjusted to evoke a $2-5 \mathrm{mV}$ PSP. Field potentials were recorded in layer II/III in response to layer IV stimulation using a patch pipette filled with ACSF.

Conditioning stimulation consisted of 200 pulses at $1 \mathrm{~Hz}$ paired with continuous postsynaptic depolarization (200 s) to -40 or $0 \mathrm{mV}$ to induce LTD or LTP, respectively (Choi et al., 2005). Only data from slices with stable recordings $(<5 \%$ change over the baseline period) were analyzed. All data are presented as the average \pm SEM normalized to the preconditioning baseline. For statistical comparisons, the LTP and LTD magnitude were taken as the average of the last $5 \mathrm{~min}$ recorded. Statistical significance was assessed using $t$ test or ANOVA followed by the Newman-Keuls post hoc tests.

\section{Results \\ Critical period of LTP and LTD in layer $I V$}

We first examined the developmental changes in LTP and LTD of the layer IV cell responses to white matter stimulation. In the barrel cortex, the plasticity of thalamic inputs to layer IV cells exhibits a brief critical period that ends by postnatal day 12 (P12) (Crair and Malenka, 1995; Feldman et al., 1998). Therefore, our study started at an early age, before the eyes are open (P8) and extended until postnatal week 4 (P35). The data from individual experiments was grouped into three sequential age categories of equal duration: P8-P12, P13-P17, P18-P23, and two later categories of P24-P28 and P32-P35.

Previous attempts to induce LTP with high-frequency stimulation and LTD with prolonged low-frequency stimulation (LFS) met with limited success in slices of rat visual cortex (Wang and Daw, 2003; Rao and Daw, 2004). However, pairing presynaptic stimulation with postsynaptic depolarization has been effective at inducing LTP and LTD in layer IV cells of the barrel and visual cortices (Crair and Malenka, 1995; Feldman et al., 1998; Crozier et al., 2007). In this study, we paired 200 stimulation pulses $(1 \mathrm{~Hz})$ with continuous depolarization to $0 \mathrm{mV}(200 \mathrm{~s})$ to elicit LTP and to $-40 \mathrm{mV}$ to elicit LTD.

The results, shown in Figure 1, indicate that paired conditioning induces changes in synaptic strength in the white matter to layer IV (WM $\rightarrow$ IV) inputs, but only in slices from young animals. In the case of LTP, the effects of age were dramatic (Fig. $1 A, B)$. The average potentiation was significant in slices prepared from 8- to 12-d-old mice (LTP, $174.3 \pm 11.2 \%$ of baseline measured 30 min after pairing; $n=9$ mice and 15 slices), reduced in slices from P13-P17 mice (LTP, $132.7 \pm 6.1 \% ; n=8$ mice and 20 slices), and negligible in slices from older mice (P18-P23, $107.9 \pm 1.8, n=5$ mice and 12 slices; P25-P31, $104.9 \pm 2.1, n=$ 4 mice and 8 slices; one-way ANOVA, $F_{(3,51)}=16.367, p<$ 0.0001). Control experiments confirmed that, as reported previously (Crair and Malenka, 1995), depolarization to $0 \mathrm{mV}$ alone induces a small potentiation, although the magnitude did not change with age (P12-P13, $117.7 \pm 5.9 \%, n=3$ mice and 6 slices; 
P20-P21, $113.7 \pm 1.9 \%, n=3$ mice and 8 slices; $p=0.55$ ) (data not shown).

Similarly, the magnitude of $\mathrm{WM} \rightarrow \mathrm{IV}$ LTD induced with pairing at $-40 \mathrm{mV}$ also declined with age (Fig 1C,D). However, the developmental loss of LTD was more gradual than the loss of LTP and was not completed until the fourth week of age (P8-P12, 72.1 $\pm 2.4, n=12$ mice, 20 slices; P13-P17, $79.2 \pm 2.3 \%, n=8$ mice, 16 slices; P18-P23, $84.3 \pm 2.2, n=10$ mice, 17 slices; P25-P31, $93.7 \pm 3.1, n=6$ mice, 10 slices; P33-P37, $100.6 \pm 2.1, n=5$ mice, 8 slices; ANOVA, $F_{(4,65)}=14.436$, $p<0.0001)$. The results indicate that the visual cortex, like the barrel cortex, has synaptic plasticity in the ascending inputs to layer IV only during a short postnatal critical period.

The dramatic loss of LTP, completed by $\sim$ P20, coincides with the developmental increase in the potency of GABAergic inhibition in layer IV (B. Jiang, unpublished observation). To determine whether increased GABAergic inhibition contributes to the loss of LTP, we included $0.5 \mathrm{~mm}$ DNDS in the recording pipette (see Materials and Methods) to block the postsynap-

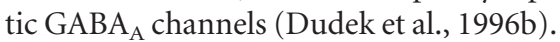
However, in the presence of DNDS, the magnitude of LTP induced in P19-P20 layer IV cells was still small (LTP, $106.5 \pm$ 2.3, $n=4$ mice, 7 slices) (Fig. $1 A, B)$ and comparable with agematched untreated cells $(p=0.90)$. DNDS has no deleterious effects on plasticity because it did not affect LTP induced in layer II/III (P19-P21, $164.0 \pm 17.9 \%, n=3$ mice, 6 slices) (described below). Thus, as shown previously for layer IV LTD (Dudek and Friedlander, 1996a), the critical period of layer IV LTP occurs independently of changes in GABAergic inhibition.

Finally, we asked whether rearing the animals in the dark from birth, which prolongs the critical period for ocular dominance plasticity, attenuates the developmental loss of synaptic plasticity in layer IV. As indicated in Figure $1 A, B$, the magnitude of LTP in cells from 22 - to 23 -d-old dark-reared mice was small (103.8 \pm $1.8 \% ; n=4$ mice, 8 slices $)$ and similar $(p=0.34)$ to the one obtained in age-matched animals reared normally. Likewise, LTD in cells from P28-P31 dark-reared mice was small (99.5 \pm $1.5 ; n=3$ mice, 6 slices) and not different from LTD of normal reared mice of comparable age $(\mathrm{P} 25-\mathrm{P} 31 ; p=0.11)$. Thus, unlike other forms of synaptic plasticity (Kirkwood et al., 1995), the developmental decline of WM-IV LTP and LTD is not arrested by sensory deprivation. These findings are consistent with the observation that dark-rearing does not affect the critical period for experience-dependent remodeling of thalamocortical inputs to layer IV (Mower et al., 1985).

\section{Persistence of LTP and LTD in layer III}

We used similar paired conditioning to assess changes in layer II/III plasticity in mouse visual cortex between the second and eighth week of age. Results from individual experiments were averaged by week (week 2, P8-P14; week 3, P15-P21, as so on, up to week 8, P57-P64). As shown in Figure 2, $A$ and $B$, LTP induced with the pairing protocol was significant at all ages and the mag- nitude was fairly constant except for a brief peak observed at the third week (P8-P14, $131.8 \pm 7.0 \%, n=15$ mice, 22 slices; $\mathrm{P} 15-$ $\mathrm{P} 21,159.2 \pm 6.5 \%, n=20$ mice, 28 slices; P22-P28, $136.0 \pm$ $4.3 \%, n=7$ mice, 11 slices; $\mathrm{P} 29-\mathrm{P} 35,135.4 \pm 8.0 \%, n=7$ mice, 12 slices; P36-P42, $132.1 \pm 6.4 \%, n=4$ mice, 6 slices; P47-P64, $132.4 \pm 7.1 \%, n=5$ mice, 8 slices; one-way ANOVA, $F_{(5,81)}=$ 2.989, $p=0.0158)$. Depolarization alone induced modest changes in the responses (P19-P20, 109.2 $\pm 3.7 \%, n=3$ mice, 9 slices; P40-P42, $104.6 \pm 6.2, n=3$ mice, 7 slices; $p=0.566$ ). However, the magnitude of LTD induced by the pairing protocol (Fig. 2C,D) was similar throughout all ages examined (P8-P14, $72.7 \pm 4.6 \%, n=6$ mice, 13 slices; P15-P21, $77.0 \pm 3.5 \%, n=7$ mice, 15 slices; P22-P28, $71.1 \pm 3.3 \%, n=7$ mice, 12 slices; P29-P35, $76.9 \pm 6.9 \%, n=3$ mice, 5 slices; P36-P42, $78.3 \pm$ $5.6 \%, n=4$ mice, 6 slices; P57-P64, $78.3 \pm 2.5 \%, n=5$ mice, 8 slices; one-way ANOVA, $\left.F_{(5,53)}=0.563, p=0.7279\right)$. These results indicate that the ascending inputs to layer II/III cells retain the capacity for bidirectional synaptic plasticity.

In rat visual cortex, layer II/III cells reportedly lose their capacity to express LTP of glutamatergic transmission by the fifth week (Yoshimura et al., 2003), suggesting a significant difference in developmental regulation of synaptic plasticity in rat and mouse. The potentiation of layer III synaptic responses in rats older than 5 weeks was attributed to LTD of fast inhibitory transmission. We examined this possibility in mouse visual cortex by asking whether pairing presynaptic stimulation with $0 \mathrm{mV}$ depolarization can also induce LTD of pharmacologically isolated GABAergic synaptic responses (IPSCs) in layer II/III cells. As shown in Figure 3, the pairing protocol did not affect the magnitude of the inhibitory synaptic responses in cells from 5 -week-old mice ( $95.9 \pm 4.7 \% ; n=2$ mice, 5 slices; $p=0.43$ ). Moreover, 

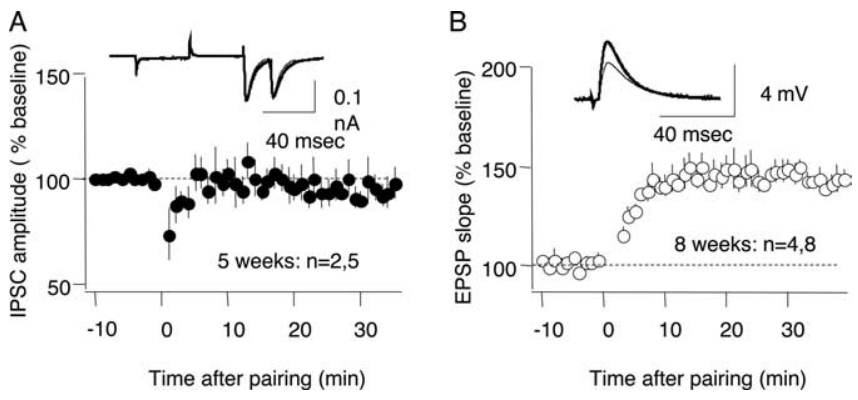

Figure 3. Pairing at $0 \mathrm{mV}$ does not affect layer II/III IPSCs in mouse visual cortex, and induces LTP of the EPSPs in cells from 8 week Sprague Dawley rats. $\boldsymbol{A}$, Effects of $0 \mathrm{mV}$ pairing on pharmacologically isolated IPSCs evoked by layer IV stimulation in 6-week-old mice layer II/III cells. $\boldsymbol{B}$, LTP of EPSPs induced by pairing at $0 \mathrm{mV}$ in layer II/III cells from rats aged P62-P64. Traces in $\boldsymbol{A}$ and $\boldsymbol{B}$ are averages of 10 consecutive responses recorded right before (thin line) and 28 min after conditioning (thick line).

under our experimental conditions, pairing at $0 \mathrm{mV}$ induced LTP in layer II/III cells from 8-week-old Sprague Dawley rats (P60P62, LTP, $146.2 \pm 4.3, n=4$ mice, 8 slices; $t$ test, $<0.0001$ ) (Fig. $3 B)$. These results suggest that the discrepancies between our findings in mice and previous studies in rats (Yoshimura et al., 2003) are not related to the species used, and probably reflect procedural differences.

The robust LTD in layer II/III cells from 6- to 8-week-old mice induced by pairing protocol is in sharp contrast with the small magnitude of LTD induced by LFS in slices from mice older than 3 weeks (Kirkwood et al., 1997; Choi et al., 2002). Interestingly, in mouse CA3 to CA1 synapses, LFS also becomes ineffective after the third week, but NMDAR-dependent LTD can still be induced with paired-pulse LFS (Lee et al., 2003). Therefore, we compared the effects of LFS ( 900 pulses, $1 \mathrm{~Hz}$ ) and paired-pulse LFS (ppLFS; 900 paired pulses $50 \mathrm{~ms}$ apart) in slices from 3-and 8-week old mice. We found that age severely reduced the magnitude of LFSinduced LTD ( 3 weeks, $73.4 \pm 5.7 \%, n=6$ mice, 11 slices; 8 weeks, $96.4 \pm 3.4 \%, n=7$ mice, 11 slices; $p=0.0032$ ) (Fig. $4 A$ ), but not that of ppLFS-induced LTD ( 3 weeks, $74.7 \pm 6.1 \%, n=5$ mice, 7 slices; 8 weeks, $77.0 \pm 5.3 \%, n=7$ mice, 13 slices; $p=$ 0.784 ) (Fig. $4 B$ ). pp LFS-induced LTD in 8 -week-old mice was completely suppressed by $100 \mu \mathrm{M}$ APV (control, $75.0 \pm 8.7 \%$, $n=3$ mice, 5 slices; APV, $98.1 \pm 7.5 \%, n=3$ mice, 6 slices; $p=$ 0.039 ) (Fig. $4 B$ ), indicating that this is an NMDA-dependent form of plasticity. These findings suggest that adult mice retain the capacity to express LTD in layer II/III, although the optimal stimulation parameters for induction might change with age. Thus, the ascending inputs to layer II-III remain plastic beyond the classically defined critical period.

\section{Discussion}

Our principal findings are that the ascending inputs to layer IV in mouse visual cortex express LTP and LTD only during a short postnatal critical period, whereas the ascending inputs to layer II/III remain plastic after puberty. A similar laminar progression of plasticity occurs in the development of the barrel cortex, with critical period of layer IV LTP/D (Crair and Malenka, 1995; Feldman et al., 1998), and layer II/III plasticity persisting into adulthood (Glazewski et al., 1998). Synaptic scaling, another activitydependent form of plasticity demonstrated in visual cortex also exhibits an early critical period in layer IV (Desai et al., 2002) and persists in layer II/III in adults (Goel and Lee, 2007). Studies of sensory deprivation conducted in vivo also show that plasticity is present in thalamic recipient cells early, and restricted to super-
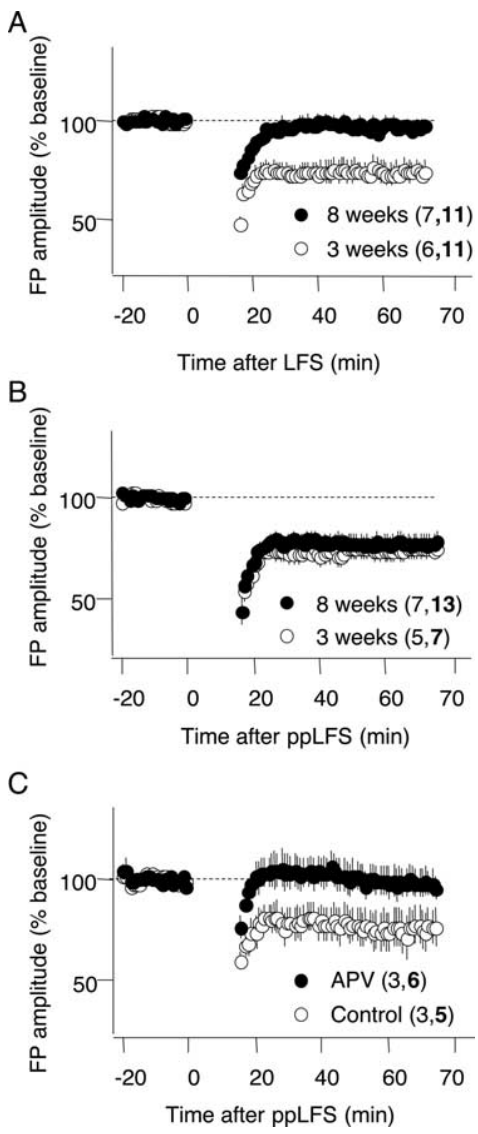

Figure 4. Developmental changes in the induction of LTD with low-frequency stimulation. $\boldsymbol{A}$, Effects of LFS ( 900 pulses, $1 \mathrm{~Hz}$ ) in the field potential (FP) recorded in slices from mice aged 3 weeks (open circles) and 8 weeks (filled circles). $\boldsymbol{B}$, Effects of ppLFS ( 900 paired pulses, $50 \mathrm{~ms}$ interval, $1 \mathrm{~Hz}$ ) in the FP recorded in slices from mice aged 3 weeks (open circles) and 8 weeks (filled circles). C, ppLFS-induced LTD in slices from 8-week-old mice (open circles) is blocked by bath application of $100 \mu \mathrm{m}$ APV (filled circles). In parentheses is the number of mice and slices (bold) included at each age $(\boldsymbol{A}, \boldsymbol{B})$ or experimental condition (C).

ficial layers later (Fox, 1992; Pham et al., 2004; Tagawa et al., 2005). All of these examples support the notion that cortical plasticity terminates in a sequential manner from layer IV to extragranular layers.

Our demonstration of a developmental loss of several forms of synaptic plasticity in layer IV agrees with the early loss of experience-induced layer IV plasticity reported in vivo (Daw et al., 1992; Fox, 1992). There are, however, examples of synaptic plasticity of adult layer IV. Tetanic stimulation of geniculate afferents in vivo induces LTP of current sinks in layer IV in adult rats (Heynen and Bear, 2001). One possibility is that the tetanus potentiates thalamic afferents onto basal dendrites of layer II/III cells located in upper layer IV. Alternatively, layer IV plasticity in adult cortex might require factors that are lost during the preparation of slices.

The mechanisms of synaptic plasticity differ across cortical layers (Wang and Daw, 2003; Rao and Daw, 2004; Crozier et al., 2007), and most likely differ in their regulation. In layer IV, the developmental loss of LTP and LTD does not correlate with changes in GABAergic transmission (Fig. 1) (see also Dudek and Friedlander 1996) or with changes in NMDAR subunit composition (Lu et al., 2001). Indeed, dark-rearing postpones the developmental changes in NMDA receptor properties that depend on subunit composition (Carmignoto and Vicini, 1992), but it does not affect the loss of LTP and LTD (Fig. 1). Thus, the critical 
period of layer IV plasticity likely involves changes downstream from the activation of NMDARs. In layer II/III, however, we propose that the machinery supporting synaptic plasticity is preserved in adults, but the induction is highly constrained by recruitment of inhibitory circuits and the action of neuromodulators (Edagawa et al., 2001; Kim et al., 2006), which may mask the ongoing presence of synaptic plasticity (Kirkwood et al., 1997; Yoshimura et al., 2003).

None of the developmental changes in LTP and LTD described here matches the time course of the classical critical period for ocular dominance plasticity (Gordon and Stryker, 1996), which peaks around p28 and finishes by P32-P35 (but see Sawtell et al., 2003; Pham et al., 2004). This timing mismatch likely reflect the complexity of multiple mechanisms affecting multiple synapses (Komatsu, 1994; Desai et al., 2002; Maffei et al., 2004) underlying ocular dominance plasticity. Thus, changes in LTP/LTD might be more informative about the availability of these mechanisms to support plasticity at a given age. For example, the persistence of LTP and LTD in layer II/III of mice might explain the remarkable degree of sensory-induced cortical plasticity that is observed in adults of this species, which manifest primarily in layers II/III (Pham et al., 2004; Tagawa et al., 2005). In this regard, it will be interesting to determine whether manipulations that reactivate plasticity in adults (He et al., 2006; Sale et al., 2007) affect primarily layer II/III cells, where LTP and LTD mechanisms remain available, or reactivate LTP and LTD in layer IV cells.

\section{References}

Bear MF, Cooper LN, Ebner FF (1987) A physiological basis for a theory of synaptic modification. Science 237:42-48.

Carmignoto G, Vicini S (1992) Activity-dependent decrease in NMDA receptor responses during development of the visual cortex. Science 258:1007-1011.

Choi S, Chang J, Jiang B, Seol GH, Min SS, Han JS, Shin HS, Gallagher M, Kirkwood A (2005) Multiple receptors coupled to PLC gate LTD in visual cortex. J Neurosci 25:11433-11443.

Choi SY, Morales B, Lee HK, Kirkwood A (2002) Absence of long-term depression in the visual cortex of glutamic acid decarboxylase-65 knockout mice. J Neurosci 22:5271-5276.

Crair MC, Malenka RC (1995) A critical period for long-term potentiation at thalamocortical synapses. Nature 375:325-328.

Crozier RA, Wang Y, Liu CH, Bear MF (2007) Deprivation-induced synaptic depression by distinct mechanisms in different layers of mouse visual cortex. Proc Natl Acad Sci USA 104:1383-1388.

Daw NW, Fox K, Satoh H, Czepita D (1992) Critical period for monocular deprivation in the cat visual cortex. J Neurophysiol 67:197-202.

Desai NS, Cudmore RH, Nelson SB, Turrigiano GG (2002) Critical periods for experience-dependent synaptic scaling in visual cortex. Nat Neurosci 5:783-789.

Dudek SM, Friedlander MJ (1996a) Developmental down-regulation of LTD in cortical layer IV and its independence of modulation by inhibition. Neuron 16:1-20.

Dudek SM, Friedlander MJ (1996b) Intracellular blockade of inhibitory synaptic responses in visual cortical layer IV neurons. J Neurophysiol 75:2167-2173.

Edagawa Y, Saito H, Abe K (2001) Endogenous serotonin contributes to a developmental decrease in long-term potentiation in the rat visual cortex. J Neurosci 21:1532-1537.

Feldman DE, Nicoll RA, Malenka RC, Isaac JT (1998) Long-term depres- sion at thalamocortical synapses in developing rat somatosensory cortex. Neuron 21:347-357.

Fox K (1992) A critical period for experience-dependent synaptic plasticity in rat barrel cortex. J Neurosci 12:1826-1838.

Glazewski S, Herman C, McKenna M, Chapman PF, Fox K (1998) Longterm potentiation in vivo in layers II/III of rat barrel cortex. Neuropharmacology 37:581-592.

Goel A, Lee HK (2007) Persistence of experience-induced homeostatic synaptic plasticity through adulthood in superficial layers of mouse visual cortex. J Neurosci 27:6692-6700.

Gordon JA, Stryker MP (1996) Experience-dependent plasticity of binocular responses in the primary visual cortex of the mouse. J Neurosci 16:3274-3286.

He HY, Hodos W, Quinlan EM (2006) Visual deprivation reactivates rapid ocular dominance plasticity in adult visual cortex. J Neurosci 26:2951-2955.

Heynen AJ, Bear MF (2001) Long-term potentiation of thalamocortical transmission in the adult visual cortex in vivo. J Neurosci 21:9801-9813.

Kim HS, Jang HJ, Cho KH, Hahn SJ, Kim MJ, Yoon SH, Jo YH, Kim MS, Rhie DJ (2006) Serotonin inhibits the induction of NMDA receptordependent long-term potentiation in the rat primary visual cortex. Brain Res 1103:49-55.

Kirkwood A, Lee HK, Bear MF (1995) Co-regulation of long-term potentiation and experience-dependent plasticity in visual cortex by age and experience. Nature 375:328-331.

Kirkwood A, Silva A, Bear MF (1997) Age-dependent decrease of synaptic plasticity in the neocortex of $\alpha$ CaMKII mutant mice. Proc Natl Acad Sci USA 94:3380-3383.

Komatsu Y (1994) Age-dependent long-term potentiation of inhibitory synaptic transmission in rat visual cortex. J Neurosci 14:6488-6499.

Lee HK, Takamiya K, Han JS, Man H, Kim CH, Rumbaugh G, Yu S, Ding L, He C, Petralia RS, Wenthold RJ, Gallagher M, Huganir RL (2003) Phosphorylation of the AMPA receptor GluR1 subunit is required for synaptic plasticity and retention of spatial memory. Cell 112:631-643.

Lu HC, Gonzalez E, Crair MC (2001) Barrel cortex critical period plasticity is independent of changes in NMDA receptor subunit composition. Neuron 32:619-634.

Maffei A, Nelson SB, Turrigiano GG (2004) Selective reconfiguration of layer 4 visual cortical circuitry by visual deprivation. Nat Neurosci 7:1353-1359.

Mower GD, Caplan CJ, Christen WG, Duffy FH (1985) Dark rearing prolongs physiological but not anatomical plasticity of the cat visual cortex. J Comp Neurol 235:448-466.

Pham TA, Graham SJ, Suzuki S, Barco A, Kandel ER, Gordon B, Lickey ME (2004) A semi-persistent adult ocular dominance plasticity in visual cortex is stabilized by activated CREB. Learn Mem 11:738-747.

Rao Y, Daw NW (2004) Layer variations of long-term depression in rat visual cortex. J Neurophysiol 92:2652-2658.

Sale A, Maya Vetencourt JF, Medini P, Cenni MC, Baroncelli L, De Pasquale R, Maffei L (2007) Environmental enrichment in adulthood promotes amblyopia recovery through a reduction of intracortical inhibition. Nat Neurosci 10:679-681.

Sawtell NB, Frenkel MY, Philpot BD, Nakazawa K, Tonegawa S, Bear MF (2003) NMDA receptor-dependent ocular dominance plasticity in adult visual cortex. Neuron 38:977-985.

Sermasi E, Tropea D, Domenici L (1999) Long term depression is expressed during postnatal development in rat visual cortex: a role for visual experience. Brain Res Dev Brain Res 113:61-65.

Tagawa Y, Kanold PO, Majdan M, Shatz CJ (2005) Multiple periods of functional ocular dominance plasticity in mouse visual cortex. Nat Neurosci 8:380-388.

Wang XF, Daw NW (2003) Long term potentiation varies with layer in rat visual cortex. Brain Res 989:26-34.

Yoshimura Y, Ohmura T, Komatsu Y (2003) Two forms of synaptic plasticity with distinct dependence on age, experience, and NMDA receptor subtype in rat visual cortex. J Neurosci 23:6557-6566. 